\title{
Kecepatan Tumbuh Benih Kelapa Sawit (Elaeis guineensis Jacq.) pada Dua Tempat Pengambilan Tanah Rawa Lebak
}

\section{(The Speed of Growing Palm Oil (Elaeis guineensis Jacq.) Seeds in Two Lebak Wetland Soil Collection Sites)}

\author{
Mahdiannoor $^{1)}$, Nur Hafizah ${ }^{2)}$ \& Heru Setiawan ${ }^{3)}$ \\ Program Studi Agroteknologi, Sekolah Tinggi Ilmu Pertanian Amuntai \\ ${ }^{1)}$ mahdi_186@yahoo.com \\ 2)fifi_bjm@yahoo.co.id \\ PT. Subur Agro Makmur Lestari Site Bajayau Kab. HSS \\ 3) comdevsam@gmail.com
}

\begin{abstract}
ABSTRAK
Seiring dengan meningkatnya kebutuhan penduduk dunia akan minyak sawit, maka perlu dipikirkan usaha peningkatan kualitas dan kuantitas produksi kelapa sawit. Salah satu faktor diantaranya adalah bahan tanam berupa bibit, untuk itu perlu tindakan kultur teknis atau perawatan bibit yang baik. Pembibitan kelapa sawit dapat dilakukan dua tahap yaitu di pembibitan awal (prenursery) dan dipindahkan ketika berumur 2,5-3 bulan apabila sudah memenuhi kriteria siap pindah ke pembibitan utama (main nursery). Penelitian ini bertujuan untuk (i) mengetahui kecepatan tumbuh benih kelapa sawit dan, (ii) mendapatkan jenis tanah terbaik untuk kecepatan tumbuh benih kelapa sawit pada dua tempat pengambilan tanah rawa lebak. Penelitian ini dilaksanakan di Desa Pangkalan Sari Kecamatan Sungai Pandan Kabupaten Hulu Sungai Utara pada bulan Juli - Agustus 2013, menggunakan Rancangan Acak Lengkap (RAL) dengan faktor tunggal. Faktor yang diteliti adalah dua tanah rawa lebak dari asal pengambilannya $(T)$ sebanyak 2 taraf dan diulang sebanyak 9 kali. Hasil penelitian menunjukkan bahwa perlakuan dua tanah rawa lebak tidak berpengaruh pada peubah pengamatan banyak tunas umur 14 dan 28 hari setelah semai (HSS), jumlah daun umur 14 HSS, dan tinggi bibit umur 14 HSS, dan berpengaruh nyata pada peubah pengamatan banyak tunas umur 42 HSS, jumlah daun umur 28 dan 42 HSS, dan berpengaruh sangat nyata pada peubah pengamatan tinggi bibit umur 28 dan 42 HSS.
\end{abstract}

Kata Kunci: Bibit, kecepatan tumbuh, benih, kelapa sawit, rawa lebak.

\begin{abstract}
Along with the increasing demand for palm oil has the world's population, it is necessary to think about efforts to increase the quality and quantity of palm oil production. One of the factors such as planting material in the form of seeds, it is necessary to act technical culture or good seed treatment. Oil palm seedlings can be done in two stages: initial seeding (prenursery) and moved at the age of 2.5-3 months when they fulfill the criteria nursery ready to move to the main (main nursery). This study aims to (i) determine the speed of growth of oil palm seeds and, (ii) obtain the best type of soil for growing speed of oil palm seeds in two places making swampy marshland. The research was conducted in the Pangkalan Sari Village, Sungai Pandan Sub-district, Hulu Sungai Utara Regency in July-August 2013, using a completely randomized design (CRD) with a single factor. Factors studied were two lebak wetland of origin of uptake (T) as much as two levels and repeated nine times. The results showed that the two treatments had no effect lebak wetlands on many shoots observation variables age 14 and 28 days after seeding(DAS), the amount of leafage of $14 \mathrm{DAS}$, seedling height $14 \mathrm{DAS}$, and significant observations on many variables shoots the age of 42 DAS, number of leaves age 28 and 42 DAS, and a very significant effect on seedling height observation variables age 28 and 42 DAS.
\end{abstract}

Keywords: Seedlings, speed of growth, seeds, oil palm, lebak wetlands.

\section{PENDAHULUAN}

Tanaman kelapa sawit (Elaeis guineensis Jacq.) saat ini merupakan salah satu jenis tanaman perkebunan yang menduduki posisi penting di sektor pertanian umumnya, dan sektor perkebunan khususnya, hal ini disebabkan karena dari sekian banyak tanaman yang menghasilkan 
minyak atau lemak, kelapa sawit yang menghasilkan nilai ekonomi terbesar per hektarnya di dunia (Khaswarina, 2001).

Melihat pentingnya tanaman kelapa sawit dewasa ini dan masa yang akan datang, seiring dengan meningkatnya kebutuhan penduduk dunia akan minyak sawit, maka perlu dipikirkan usaha peningkatan kualitas dan kuantitas produksi kelapa sawit secara tepat agar sasaran yang diinginkan dapat tercapai. Salah satu diantaranya adalah bahan tanam berupa bibit, untuk itu perlu tindakan kultur teknis atau perawatan bibit yang baik (Haekal, 2000).

Permasalahan tanah rawa lebak pada pembibitan kelapa sawit adalah sebagian tanah melumpur, kandungan lempung tanah tinggi, atau gambut tebal dengan lapisan bawah dapat berupa lapisan pirit $\left(\mathrm{FeS}_{2}\right)$ yang berpotensi masam, serta banjir yang tidak tentu kapan datangnya juga menjadi masalah dalam pembibitan (PT. Tribuana Mas, 2013).

Penelitian ini bertujuan untuk (i) mengetahui kecepatan pertumbuhan dan (ii) mendapatkan jenis tanah terbaik untuk kecepatan pertumbuhan benih kelapa sawit (Elaeis guineensis Jacq.) pada dua tempat pengambilan tanah rawa lebak.

\section{METODE PENELITIAN}

Percobaan ini dilaksanakan di Desa Pangkalan Sari Kecamatan Sungai Pandan

Tabel 1. Hasil uji beda rata-rata banyak tunas bibit kelapa sawit

\begin{tabular}{lccc}
\hline \multicolumn{1}{c}{ Perlakuan } & \multicolumn{3}{c}{ Banyak tunas (tunas) } \\
\cline { 2 - 4 } & 14 hari & 28 hari & 42 hari \\
\hline $\mathrm{t}_{1}$ (Tanah Pawalutan) & 2,33 & 2,89 & $3,78^{\mathrm{b}}$ \\
\hline $\mathrm{t}_{2}$ (Tanah Bajayau) & 2,22 & 2,56 & $3,11^{\mathrm{a}}$ \\
\hline
\end{tabular}

Keterangan : Nilai rata-rata yang diikuti huruf yang berbeda menunjukkan perlakuan tersebut berbeda berdasarkan uji DMRT pada taraf nyata $5 \%$.

Dari Tabel 1 terlihat bahwa pada umur 14 HSS, perlakuan $t_{1}$ menghasilkan rata-rata 2,33 tunas bibit kepala sawit yang tidak berbeda nyata dengan $\mathrm{t}_{2}$ yaitu 2,22 tunas. Pada umur 28 HSS, perlakuan $\mathrm{t}_{1}$ menghasilkan rata-rata 2,89 tunas bibit kepala sawit yang juga tidak berbeda dengan $\mathrm{t}_{2}$ yaitu 2,56 tunas. Dan pada umur $42 \mathrm{HSS}$, perlakuan $t_{1}$ sebagai perlakuan terbaik menghasilkan rata-rata 3,78 tunas bibit
Kabupaten Hulu Sungai Utara, pada bulan Juli-Agustus 2013. Menggunakan Rancangan Acak Lengkap (RAL) faktor tunggal. Faktor yang diuji adalah dua tempat pengambilan tanah rawa lebak (T) sebanyak 2 taraf, yang terdiri dari $\mathrm{t}_{1}=$ Tanah Desa Pawalutan Kecamatan Banjang Kabupaten HSU dan $t_{2}=$ Tanah Desa Bajayau Kecamatan Daha Barat Kabupaten HSS dengan 9 ulangan sehingga total ada 18 satuan percobaan dengan peubah pengamatan adalah kecepatan tumbuh tunas, tinggi bibit dan jumlah daun yang dihitung pada saat tanaman berumur 14 hari, 28 hari, dan 42 hari setelah semai (HSS). Analisis yang digunakan adalah uji $\mathrm{F}$ dan uji nilai tengah perlakuan dengan menggunakan DMRT pada taraf uji $5 \%$.

\section{HASIL DAN PEMBAHASAN}

\section{Hasil}

\section{Banyak Tunas}

Berdasarkan analisis ragam diketahui bahwa perlakuan dua jenis tanah yaitu tanah Pawalutan ( $\left.\mathrm{t}_{1}\right)$ dan tanah Bajayau ( $\left.\mathrm{t}_{2}\right)$ tidak berpengaruh terhadap peubah pengamatan banyak tunas umur 14 dan 28 HSS, dan berpengaruh nyata pada umur 42 HSS. Ratarata banyak tunas bibit kelapa sawit dapat dilihat pada Tabel 1. 
jumlah daun bibit kelapa sawit dapat dilihat pada Tabel 2.

Tabel 2. Hasil uji beda rata-rata jumlah daun bibit kelapa sawit

\begin{tabular}{lccc}
\hline \multicolumn{1}{c}{ Perlakuan } & \multicolumn{3}{c}{ Jumlah daun (helai) } \\
\cline { 2 - 4 } & 14 hari & 28 hari & 42 hari \\
\hline $\mathrm{t}_{1}$ (Tanah Pawalutan) & 1,44 & $2,44^{\mathrm{b}}$ & $3,22^{\mathrm{b}}$ \\
\hline $\mathrm{t}_{2}$ (Tanah Bajayau) & 1,22 & $2,00^{\mathrm{a}}$ & $2,78^{\mathrm{a}}$ \\
\hline
\end{tabular}

Keterangan : Nilai rata-rata yang diikuti huruf yang berbeda menunjukkan perlakuan tersebut berbeda berdasarkan uji DMRT pada taraf nyata $5 \%$.

Dari Tabel 4 terlihat bahwa pada umur 14 HSS, perlakuan $t_{1}$ menghasilkan rata-rata 1,44 helai daun bibit kepala sawit yang tidak berbeda dengan $t_{2}$ yaitu 1,22 helai. Pada umur 28 hari, perlakuan $\mathrm{t}_{1}$ sebagai perlakuan terbaik menghasilkan rata-rata 2,44 helai daun bibit kelapa sawit yang berbeda dengan $\mathrm{t}_{2}$ yaitu 2,00 helai daun. Dan pada umur 42 HSS, perlakuan $t_{1}$ juga sebagai perlakuan terbaik menghasilkan rata-rata 3,22 helai daun bibit kepala sawit yang juga berbeda dengan $t_{2}$ yaitu 2,78 helai daun.

\section{Tinggi Bibit}

Berdasarkan hasil analisis ragam diketahui bahwa perlakuan dua jenis tanah yaitu tanah Pawalutan $\left(\mathrm{t}_{1}\right)$ dan tanah Bajayau $\left(\mathrm{t}_{2}\right)$ tidak berpengaruh terhadap peubah pengamatan tinggi tanaman umur 14 hari, dan berpengaruh sangat nyata pada umur 28 dan 42 hari. Rata-rata tinggi bibit kelapa sawit dapat dilihat pada Tabel 3.

Tabel 5. Hasil uji beda rata-rata tinggi bibit kelapa sawit

\begin{tabular}{lccc}
\hline \multicolumn{1}{c}{ Perlakuan } & \multicolumn{3}{c}{ Tinggi bibit $(\mathrm{cm})$} \\
\cline { 2 - 4 } & 14 hari & 28 hari & 42 hari \\
\hline $\mathrm{t}_{1}$ (Tanah Pawalutan) & 9,67 & $14,00^{\mathrm{b}}$ & $18,67^{\mathrm{b}}$ \\
\hline $\mathrm{t}_{2}$ (Tanah Bajayau) & 9,00 & $12,56^{\mathrm{a}}$ & $15,67^{\mathrm{a}}$ \\
\hline
\end{tabular}

Keterangan : Nilai rata-rata yang diikuti huruf yang berbeda menunjukkan perlakuan tersebut berbeda berdasarkan uji DMRT pada taraf nyata $5 \%$

Dari Tabel 5 terlihat bahwa pada umur 14 HSS, perlakuan $t_{1}$ menghasilkan rata-rata tinggi bibit kepala sawit $9,67 \mathrm{~cm}$ yang tidak berbeda dengan $\mathrm{t}_{2}$ yaitu $9,00 \mathrm{~cm}$. Pada umur 28 HSS, perlakuan $\mathrm{t}_{1}$ sebagai perlakuan terbaik menghasilkan rata-rata tinggi bibit kelapa sawit 14,00 cm yang berbeda dengan $\mathrm{t}_{2}$ yaitu $12,56 \mathrm{~cm}$. Dan pada umur $42 \mathrm{HSS}$, perlakuan $\mathrm{t}_{1}$ juga sebagai perlakuan terbaik menghasilkan rata-rata tinggi bibit kelapa sawit $18,67 \mathrm{~cm}$ yang juga berbeda dengan $\mathrm{t}_{2}$ yaitu $15,67 \mathrm{~cm}$.

\section{Banyak Tunas}

\section{Pembahasan}


membentuk pori kecambah, kemudian embrio akan membentuk jaringan yang secara cepat berkembang menjadi plumula (pucuk daun) dan radikula (akar). Aktivitas enzim lipase terdapat pada saat biji mengalami masa dormansi dan pada saat biji mengalami proses perkecambahan (Abigor et. al., 2002).

Hasil analisis Laboratorium Kimia, Fisika, dan Biologi Tanah Fakultas Pertanian Unlam (2018) menunjukkan bahwa tanah Pawalutan $\left(\mathrm{t}_{1}\right)$ mengandung unsur nitrogen yang sedang yaitu $0,50 \%$, unsur fosfor yang tinggi yaitu $11,29 \mathrm{ppm}$, dan unsur kalium yang juga tinggi yaitu 55,90 ppm. Selain itu, Ca yang terkandung dalam tanah ini juga tinggi yaitu $40,49 \%$.

Menurut Novizan (2002), unsur fosfor dari dalam tanah ini dapat merangsang pertumbuhan awal bibit tanaman, karena unsur ini mampu merangsang perkembangan akar. Seiring dengan pertumbuhan akar bibit kelapa sawit ini, unsur hara yang ada dalam tanah seperti nitrogen, $\mathrm{Ca}$, dan magnesium dapat diserap secara optimal. Unsur nitrogen berfungsi dalam pembentukan tunas, nitrogen yang diserap melalui akar dikirim ke pucuk. Selama proses pertumbuhan dan perkembangan tanaman memerlukan berbagai unsur hara seperti nitrogen yang dapat meningkatkan pertumbuhan vegetatif akar, batang, daun, cabang tanaman, memberikan warna hijau pada daun tanaman yang berhubungan dengan klorofil dalam peranannya pada proses fotosentesis, nitrogen juga berperan dalam mengatur penggunaan fosfor dan kalium pada suatu tanaman. Adapun efek samping dari kekurangan unsur nitrogen yaitu tanaman tumbuh kerdil, sistem perakaran terbatas serta warna daun yang pucat (Wijaya, 2008).

Tingginya kandungan $\mathrm{Ca}$ pada tanah Pawalutan $\left(\mathrm{t}_{1}\right)$ mampu menghindari matinya titik tumbuh pada pucuk dan akar, sehingga bibit kelapa sawit dapat tumbuh dengan baik. $\mathrm{Ca}$ berperan dalam proses pembelahan dan perpanjangan sel, dan mengatur distribusi hasil fotosintesis. Sedangkan $\mathrm{Mg}$ yang terkandung diperlukan oleh semua bagian hijau drai tanaman, sebab merupakan bagian penyusun klorofil. Magnesium juga memegang peranan pada transportasi fosfat dalam tanaman, magnesium di dalam tanah berasal dari dekomposisi batuan yang berisi mineral, antar lain biotit, dolomit, serpentin, klorit, dan olivin. Magnesium berfungsi juga sebagai regulator (pengaturan) dalam penyerapan unsur lain, seperti fosfor dan kalium. Unsur hara fosfor dan kalium ini juga dijelaskan oleh Khaswarina (2001) bahwa unsur fosfor berperan dalam proses pembelahan sel untuk membentuk organ tanaman, dan unsur kalium dalam hal ini juga berperan dalam merangsang titik tumbuh tanaman.

Berdasarkan hasil uji beda rata-rata pada taraf $5 \%$ didapatkan perlakuan terbaik pada $t_{1}$. Hal ini sesuai dengan kondisi hara pada tanah Bajayau. Unsur hara yang terkandung pada tanah Bajayau ( $\left.\mathrm{t}_{2}\right)$ lebih rendah dibanding unsur hara pada tanah Pawalutan $\left(\mathrm{t}_{1}\right)$, terutama kandungan nitrogennya yang sangat rendah yaitu $0,08 \%$. Rendahnya kandungan unsur nitrogen ini menyebabkan banyaknya tunas yang terbentuk juga lebih sedikit dibanding banyaknya tunas pada perlakuan $\mathrm{t}_{1}$.

\section{Jumlah Daun}

Hasil analisis ragam menunjukkan bahwa perlakuan dua jenis tanah yaitu tanah Pawalutan dan tanah Bajayau tidak berpengaruh terhadap peubah pengamatan jumlah daun umur 14 HSS, dan berpengaruh nyata pada peubah pengamatan jumlah daun umur 28 dan 42 hari. Pada umur 14 HSS tidak menunjukkan adanya pengaruh perlakuan karena bibit kelapa sawit baru mulai tumbuh. Penyerapan unsur hara oleh akar dari dalam tanah belum optimal, walaupun pada perlakuan $\mathrm{t}_{1}$ kandungan unsur hara lebih tinggi dari perlakuan $\mathrm{t}_{2}$.

Pada umur 28 hari dan 42 HSS, akar bibit kelapa sawit sudah berkembang dan mampu menyerap unsur hara dari dalam tanah secara optimal. Hal ini dibuktikan dengan adanya peningkatan jumlah daun bibit kelapa sawit. Pada perlakuan $\mathrm{t}_{1}$ rata-rata jumlah daun umur 28 HSS yaitu 2,44 helai daun dan pada umur 42 HSS 3,22 helai, yang berbeda nyata dengan rata-rata jumlah daun pada perlakuan $\mathrm{t}_{2}$.

Kandungan unsur hara nitrogen yang lebih tinggi pada tanah Pawalutan ( $\left.\mathrm{t}_{1}\right)$ dibanding tanah Bajayau $\left(\mathrm{t}_{2}\right)$ menyebabkan pertumbuhan daun bibit kelapa sawit pada 
perlakuan $\mathrm{t}_{1}$ lebih banyak dari pertumbuhan daun pada $t_{2}$. Unsur nitrogen yang diserap melalui akar kemudian diteruskan ke daun digunakan untuk membentuk senyawa klorofil. Maryani dan Gusmawartati (2012) menyatakan bahwa tanaman yang mampu menghasilkan fotosintat yang lebih tinggi akan mempunyai banyak daun, karena hasil fotosintat akan digunakan untuk membentuk organ seperti daun dan batang.

Fotosintat yang dihasilkan tanaman melalui proses fotosintesis ada kaitannya dengan kandungan dan peranan unsur hara makro dan mikro. Nitrogen sangat menunjang pertumbuhan sel-sel daun dan kalium untuk dinding sel daun. Dengan semakin banyaknya pembentukan klorofil pada daun maka proses fotosintesis akan meningkat sehingga dapat meningkatkan fotosintat (Gusniwati et. al., 2012). Menurut Gardner et al., (1991) nitrogen dapat merangsang daun bertambah luas, dengan semakin luasnya daun maka meningkat pula penyerapan cahaya oleh daun dengan demikian fotosintat yang dihasilkan semakin banyak.

Berdasarkan hasil uji beda rata-rata pada taraf $5 \%$ didapatkan perlakuan terbaik pada $t_{1}$. Hal ini disebabkan unsur hara yang terkandung pada tanah Bajayau ( $\left.\mathrm{t}_{2}\right)$ lebih rendah dibanding unsur hara pada tanah Pawalutan ( $\left.\mathrm{t}_{1}\right)$, dan adanya kandungan Fe dan Al yang tinggi pada tanah Bajayau yang menyebabkan sebagian unsur hara dalam tanah tidak tersedia untuk tanaman. Menurut Engelstad (1997), adanya kandungan $\mathrm{Fe}$ dan Al pada tanah akan membentuk senyawasenyawa kompleks yang sukar larut, sehingga menyebabkan unsur hara tidak tersedia untuk tanaman. Besi (Fe) tinggi menyebabkan nekrosis yang ditandai dengan munculnya bintik-bintik hitam pada daun sedangkan pada Aluminium (Al) berlebih dalam tanah dapat menimbulkan hambatan bagi pertumbuhan tanaman secara langsung maupun tidak langsung. Secara langsung tingginya kadar $\mathrm{Al}$ dalam tanah dapat meracuni tanaman, sedangkan secara tidak langsung $\mathrm{Al}$ dapat sebagai pensuplai ion $\mathrm{H}$ yang pada akhirnya mempengaruhi $\mathrm{pH}$ tanah sehingga $\mathrm{pH}$ rendah dan mengakibatkan tidak tersedianya unsur hara. Al yang tinggi juga dapat mengikat unsur-unsur lain seperti fospor (P) dan boron (B) sehingga tidak tersedia bagi tanaman.

\section{Tinggi Bibit}

Hasil analisis ragam menunjukkan bahwa perlakuan dua jenis tanah yaitu tanah Pawalutan dan tanah Bajayau juga tidak berpengaruh terhadap peubah pengamatan tinggi bibit umur 14 HSS, dan berpengaruh sangat nyata pada umur 28 dan 42 HSS. Dari rata-rata tinggi bibit yang dihasilkan, cenderung perlakuan tanah Pawalutan $\left(\mathrm{t}_{1}\right)$ menunjukkan tinggi bibit lebih tinggi dibandingkan perlakuan tanah Bajayau $\left(\mathrm{t}_{2}\right)$. Namun perlakuan dua jenis tanah ini tidak memperlihatkan tinggi bibit yang berbeda pada umur 14 HSS, hal ini selain disebabkan oleh penyerapan unsur hara dari dalam tanah yang belum optimal, juga disebabkan belum terbentuknya daun yang sempurna sehingga fotosintat yang dihasilkan pada proses fotosintesis masih sedikit.

Perlakuan dua jenis tanah memperlihatkan tinggi bibit kelapa sawit yang berbeda pada umur 28 dan $42 \mathrm{HSS}$. Hal ini disebabkan unsur hara dalam tanah sudah bisa diserap akar secara optimal, seperti unsur nitrogen yang berperan dalam merangsang pertumbuhan tinggi tanaman. Menurut Wardati dan Elfina (2008), nitrogen merupakan penyusun enzim-enzim, asam amino, asam nukleat, karbohidrat, sehingga pembentukan sel-sel baru bagi tanaman akan berlangsung dengan optimal.

$$
\text { Adanya peningkatan dalam }
$$

pertambahan tinggi bibit erat kaitannya dengan pertambahan jumlah daun dimana dengan bertambahnya jumlah daun bibit kelapa sawit, maka proses fotosintesis akan meningkat sehingga fotosintat yang dihasilkan bertambah besar pula. Karbohidrat yang dihasilkan sangat berperan penting dalam membangun sel-sel baru, bahan penyusun dinding sel dan berguna untuk pertumbuhan bagian-bagian yang aktif membelah. Harjadi (1984) dalam Gusniwati et. al. (2012) menegaskan bahwa, fotosintat yang dihasilkan dalam proses fotosintesis ditranslokasikan kebagian organ tanaman yang sel-selnya mengalami pembesaran. 
Bagian yang aktif dari pembesaran sel adalah jaringan meristem.

Kapasitas tukar kation suatu jenis tanah adalah kemampuan tanah untuk menyerap kation-kation yang dapat dipertukarkan pada permukaan koloid-koloid tanah yang bermuatan negatif. Nilai KTK berkaitan erat dengan kesuburan tanah, dimana tanah dengan nilai KTK tinggi mampu menyerap dan menyediakan unsur hara lebih baik dari pada tanah dengan nilai KTK rendah. Besarnya KTK sangat dipengaruhi oleh jumlah dan jenis liat, serta humus tanah. (Hardjowigeno, 2002).

Kalium dalam tanah umumnya ditemukan dalam bentuk mineral yang kompleks. Bentuk tersebut mudah berubah bila tercuci oleh air yang mengandung $\mathrm{CO}_{2}$ atau asam-asam lainnya. Sebagian besar kandungan kalium dalam tanah berasal dari pelapukan batuan yang mengandung kalium seperti mika dan feldspar (menghasilkan ion kalium bagi tanaman) Berfungsi dalam proses fotosintesa, pengangkutan hasil asimilasi, enzim dan mineral termasuk air. Kalium berfungsi meningkatkan daya tahan kekebalan tanaman terhadap penyakit dan tanaman yang kekurangan unsur kalium gejalanya : batang dan daun menjadi lemas/rebah, daun berwarna hijau gelap kebiruan tidak hijau segar dan sehat, ujung daun menguning dan kering, timbul bercak coklat pada pucuk daun (Hardjowigeno, 2002).

$\mathrm{pH}$ tanah atau tepatnya $\mathrm{pH}$ larutan tanah sangat penting karena larutan tanah mengandung unsur hara seperti nitrogen $(\mathrm{N})$, potassium/kalium (K), dan fospor $(\mathrm{P})$ dimana tanaman membutuhkan dalam jumlah tertentu untuk tumbuh, berkembang, dan bertahan terhadap penyakit. Jika $\mathrm{pH}$ larutan tanah meningkat hingga di atas 5,5; nitrogen (dalam bentuk nitrat) menjadi tersedia bagi tanaman. Di sisi lain fospor akan tersedia bagi tanaman pada $\mathrm{pH}$ antara 6,0 hingga 7,0.

Derajat $\mathrm{pH}$ dalam tanah juga menunjukkan keberadaan unsur-unsur yang bersifat racun bagi tanaman. Jika tanah masam akan banyak ditemukan unsur alumunium (Al) yang selain meracuni tanaman juga mengikat phosphor sehingga tidak bisa diserap tanaman. Selain itu pada tanah masam juga terlalu banyak unsur mikro yang bisa meracuni tanaman (Hardjowigeno, 2002).

Tingkat kejenuhan basa nilainya dalam bentuk persen, mencerminkan akumulasi susunan kation. Peningkatan nilai persen kejenuhan basa mencerminkan semakin tingginya kandungan basa-basa tanah pada posisi nilai $\mathrm{pH}$ tanah yang menyebabkan nilai kesuburan kimiawi optimal secara menyeluruh. Nilai kesuburan kimiawi secara sederhana dicermnkan oleh nilai $\mathrm{pH}$, karena nilai $\mathrm{pH}$ akan mampu mempengaruhi dan mencerminkan aktifitas kimiawi sekaligus aktifitas biologis dan kondisi fisik di dalam tanah (Hardjowigeno, 2002).

Bahan organik adalah bagian dari tanah yang merupakan suatu sistem kompleks dan dinamis, yang bersumber dari sisa tanaman atau binatang yang terdapat di dalam tanah yang terus menerus mengalami perubahan bentuk, karena dipengaruhi oleh faktor biologis, fisika, dan kimia. Bahan organik tanah adalah semua jenis senyawa organik yang terdapat di dalam tanah, termasuk fraksi bahan organik ringan, biomassa mikroorganisme, bahan organik didalam air, dan bahan organik yang stabil atau humus. Kadar C-organik tanah cukup bervariasi, tanah mineral biasanya mengandung C-organik antara 1 hingga 9\%, sedangkan tanah gambut dan lapisan organik tanah hutan dapat mengandung 40 sampai $50 \%$ C-organik (Hardjowigeno, 2002).

Berdasarkan hasil uji beda rata-rata pada taraf $5 \%$ didapatkan perlakuan terbaik pada $t_{1}$ pada tinggi tanaman. Hal ini disebabkan unsur hara yang terkandung pada tanah Bajayau ( $\left.\mathrm{t}_{2}\right)$ berada dalam keadaan tidak seimbang. Gusniwati et. al., (2012) menegaskan bahwa adanya hara yang berlebihan belum tentu meningkatkan pertumbuhan tanaman. Perlakuan tanah Bajayau $\left(\mathrm{t}_{2}\right)$ menunjukkan respon pertumbuhan yang rendah pada tinggi bibit karena diduga adanya unsur yang berlebih atau tidak seimbang diantaranya adanya kandungan unsur hara nitrogen yang rendah, nitrogen mempengaruhi penyerapan unsur hara lainnya oleh tanaman sehingga 
rendahnya kandungan nitrogen ini memperlambat penyerapan unsur hara lain terutama fosfor dan kalium. Selain itu Fe dan $\mathrm{Al}$ yang tinggi menyebabkan beberapa unsur hara yang terikat dengan ion $\mathrm{Fe}$ dan $\mathrm{Al}$ tersebut seperti unsur hara fosfor yang cenderung tidak tersedia akibat terikat oleh Fe dan Al.

Hal ini sejalan dengan pendapat Novizan (2002), bahwa selain jumlah unsur hara secara individu, jumlah relatif salah satu unsur hara terhadap unsur hara yang lain juga berpengaruh pada ketersediaan unsur hara. Dimana jumlah salah satu unsur hara harus berada dalam keadaan seimbang dengan unsur hara yang lain supaya penyerapan oleh tanaman menjadi optimal. Tinggi rendahnya hasil tanaman juga dipengaruhi faktor faktor selama tanaman itu mengalami pertumbuhan. Faktor dari dalam tanah antara lain ketersediaan unsur hara, air, suhu, tanah dan sebagainya. Sedangkan dari atmosfer antara lain suhu, udara, kelembaban, intensitas cahaya matahari, dan curah hujan

\section{KESIMPULAN DAN SARAN}

Diketahui terdapat kecepatan
pertumbuhan benih kelapa sawit (Elaeis
guineensis Jacq.) pada dua tempat
pengambilan tanah rawa lebak dan
didapatkan tanah rawa lebak yang terbaik
untuk kecepatan pertumbuhan benih kelapa
sawit (Elaeis guineensis Jacq.) adalah tanah
Desa Pawalutan $\left(\mathrm{t}_{1}\right)$.

\section{UCAPAN TERIMAKASIH}

Ucapan terimaksih kepada PT Subur Agro Makmur Site Bajayau Kab. Hulu Sungai Selatan atas pembiayaan penelitian ini melalui Penelitian Community Development Tahun 2018 dengan kontrak Nomor 001/CD-Kks/SAM/II/2008 tanggal 1 Februari 2018.

\section{DAFTAR PUSTAKA}

Abigor RD, Uadia PO, Foglia TA, Haas MJ, Scott K, Savary BJ, 2002. Partial purification and properties of lipase from germinating seeds of Jatropha curcas L. Journal of The American Oil Chemists' Society 79(11).

Engelstad, O. P. 1997. Teknologi dan Penggunaan Pupuk. Gadjah Mada University Press. Yogyakarta.

Gardner, R., Pearce, dan R.L. Mitchell, 1991. Fisiologi Tanaman Budidaya. Universitas Indonesis - Press Jakarta. Jakarta.

Gusniwati., Salim, H., dan Mandasari, J. 2012. Kelapa sawit (Elais guineensis Jaqc.) di pembibitan utama dengan perbedaan kombinasi pupuk cair Nutrifarm dan NPKMg. Jurnal Bioplante Volume 1 No. 1.

Haekal, M. 2000. Respon pertumbuhan bibit kelapa sawit terhadap pemupukan pada media tumbuh alang-alang dengan inokulasi Trichordema viride. http://repository.ipb.ac.id. Diakses tanggal 20 Mei 2013.

Hardjowigeno, S. H. 2003. Ilmu Tanah. Akademika Pressindo. Jakarta

Laboratorium Kimia, Fisika dan Biologi Tanah 2012. Hasil Analisis Tanah. Fakultas Pertanian UNLAM Banjarbaru.

Khaswarina, S. 2001. Keragaan bibit kelapa sawit terhadap pemberian berbagai kombinasi pupuk di pembibitan utama. Jurnal Natur Indonesia Volume 3 No.2.

Maryani, A.T. dan Gusmawartati 2010. Pengaruh volume pemberian air terhadap pertumbuhan bibit kelapa sawit di pembibitan utama. Jurnal Agroteknologi, Volume 1 No. 1.

Novizan. 2002. Petunjuk Pemupukan yang Efektif. Agromedia. Jakarta.

PT. Tribuana Mas. 2013. Pembibitan Kelapa Sawit. Marabahan.

Wijaya, K.A. 2008. Nutrisi Tanaman Sebagai Penentu Kualitas Hasil dan Resintensi Alami Tanaman. Prestasi Pustaka. Jakarta.

Wardati dan Elfina, Y. 2008. Serapan NPK bibit kelapa sawit dengan aplikasi 
Dregs dan Trichoderma sp pada pembibitan awal di medium gambut. Jurnal Sagu Volume 7 No. 1. 